\title{
THE COMPARISON OF MATCH FILTERING AND SPECTRAL INFORMATION DIVERGENCE METHODS FOR DETECTING OF WATER QUALITY
}

DOI: http://dx.doi.org/10.18509/GBP.2018.48

UDC: 528.88:628.11.032(560)

\author{
Onder Gursoy ${ }^{1}$ \\ Rutkay Atun ${ }^{1}$ \\ ${ }^{1}$ Cumhuriyet University, Geomatics Engineering Department, Turkey \\ ${ }^{2}$ Cumhuriyet University, Environmental Engineering Department, Turkey \\ ${ }^{3}$ Cumhuriyet University, Geological Engineering Department, Turkey
}

\begin{abstract}
The quality of water resources, which are very important for environmental and human health, can now be examined together with remote sensing technology. Management of water resources is crucial for the development of countries. In our country, the quality of the water resources is getting worse due to the development of the industry and other factors. There are many spectral classification methods in remote sensing, and the applicability of two spectral classification methods is aimed to evaluate water quality in this study. Within the scope of this study, İmranlı region of Kizılırmak River was examined. High resolution satellite image in operation CHRIS Proba is provided free of charge from European Space Agency. The spectroradiometer measurement points were determined to obtain the water sample. From these points, local measurements were made with the spectroradiometer simultaneously with transition of the satellite. The quality evaluation was carried out by analyzing the water samples in the laboratory. As a result of measurements made with the spectroradiometer, reflectance from the measurements was resampled at the Chris PROBA band intervals and a reference for classification was established. Using this data, applicability of a spectral classification method, Match Filtering and Spectral Information Divergence, was tested in order to evaluate water quality.
\end{abstract}

Keywords: Water quality assessment, CHRIS Proba, ground measurement, remote sensing.

\section{TRODUCTION}

Water is one of the most essential compounds for our life. Access to clean water has become more difficult nowadays because of the increase in population, the commissioning of the global warming process and the presence of some pollutants. The pollution of water resources is either due to natural factors or human factors. Natural factors include the erosion of the rocks in the water base over time and their chemical reaction with water. At the same time, due to the decrease in the amount of water, the rate of pollution of these rocks is increased. Human factors include urbanization, industrialization, population growth, agricultural chemicals and chemical fertilizers. As a result of the evaluation of all these pollutants, management of clean water is of utmost importance for sustainable development and it is therefore necessary to protect existing resources and to identify and purify contaminated resources. 
With the development of technology, the monitoring and analysis of water resources has become faster and less costly. One of these methods is remote sensing. Using satellitebased remote sensing, concentrations of different water components of water mass, colored dissolved organic matter, chlorophyll, total suspended solids can be measured [1, $2,3]$. Remote sensing deals with water and agricultural management in water related issues, such as the determination of water pollution and water content $[4,5]$. In this study, it is aimed to determine and monitor water pollution with ground measurements, high resolution satellite image and laboratory data.

\section{STUDY AREA}

Kizilirmak is Turkey's longest river, which is $1355 \mathrm{~km}$, born to the country and pours to Black Sea [6]. Imranli region of the river and Imranli dam is selected as study area (figure 1). The Imranli dam is also built on the Kizilirmak River and is fed by rivers waters. The dam and the river is the most important water source of the region.

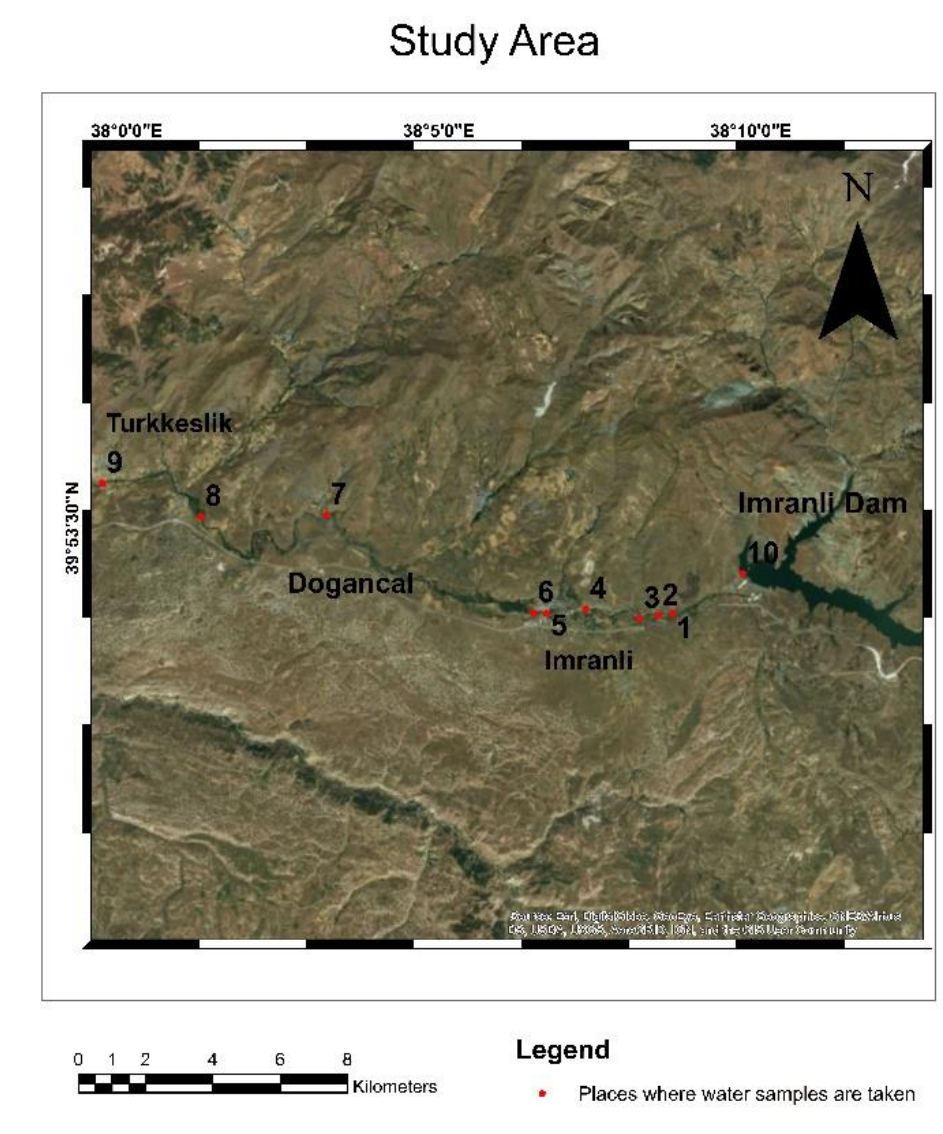

Figure 1. Study Area

\section{MATERIALS}

Ground measurements were made with ASD's FieldSpec 4, which measures between 350 and $2500 \mathrm{~nm}$. Chris PROBA, available free of charge from the European Space Agency, was used as the satellite image. Chris PROBA provides high spatial resolution in the near 
infrared and visible spectral region and has 18 bands with a spatial resolution of $18 \mathrm{~m} \mathrm{[7],}$ [8].

\section{METHOD}

First of all, the radiometric and atmospheric correction was made to ready the Chris PROBA satellite image to the required analysis. Corrections were made through BeamVISAT software. Then, the geometric correction of the images was carried out according to the UTM projection system 37th zone. Water samples were taken from various places in the dam and the river and measurements were made by spectroradiometer. This process was performed for the designated 10 locations. Water samples were taken to the laboratory environment, where criteria such as KOI content and electrical conductivity were tested. The quality analysis of water samples was carried out on the basis of the Water Pollution Control Regulation of the Ministry of Environment and Urbanization [9].

It was determined that the water samples taken from 1, 2, 3, 4, 6, 7, 10 locations were of first quality and the samples taken from 5 and 8 locations were of second quality according to KOI content. In the evaluation according to electrical conductivity from the same points 1, 2, 3, 4, 6, 7, 10 sites were found to be first quality water and samples from 5 and 8 locations were second quality.

Satellite images were obtained simultaneously on the date of spectroradiometric measurements. Since the spectroradiometer measurements between 350 and 2500 nanometer wavelength range, they were resampled to the bandwidth of the Chris PROBA satellite image. The spectral signatures required for classification were obtained by resampling the spectroradiometric reflectance to the CHRIS Proba band intervals.

Spectral classification methods such as Match Filtering (MF) and Spectral Information Divergence (SID) were used to evaluate water quality. SID is a method that uses the spectral histogram to identify the probability distribution and accepts each pixel as a random variable. Spectral similarity between two pixels is measured by the inconsistency of the probability conduct between spectra [10]. Match filtering is a technique that estimates the abundance of user-defined end-members from a set of reference spectra by using a partial unmixing of spectra [11].

\section{RESULTS AND DISCUSSION}

MF and SID classification algorithms have been applied to the image and thus first and second quality water classes have been obtained. According to the results, it has been monitored that the water quality of the river is generally first quality. The water in Imranli dam also has been determined to be second quality water. It has been understood that the impurity ratio at Imranli dam is better monitored by the SID algorithm compared with the SAM. The fact that the dam is fed from other rivers, the rocks in the dam are dissolved in the water and the people who throw their waste to the dam are also among the factors causing pollution in the dam.

\section{REFERENCES}

[1] Babin M \& Stramski D. Light absorption by aquatic particles in the near-infrared spectral region, Limnology and Oceanographyce, USA, vol. 47, pp 911-955, 2002. 
[2] Hu C, Lee Z, Ma R, Yu KL, Dshang S. Moderate resolution imaging spectroradiometer (MODIS) observation of cyanobacteria blooms in Taihu Lake, China, Journal of Geophysical Research, USA, vol. 115, pp 1-22, 2010.

[3] Kutser T, Paavel BC, Verpooter C, Kauer T, Vahmae E. Reomte sensing of water quality in optically complex lakes, International Archive of the Photogrammetryi Remote Sensing and Spatial Information Sciences, Australia, vol. 39, pp 165-169, 2012.

[4] Giardino C, Candiani G, Bresciani M, Lee Z, Gagliano S, Pepe M. BOMBER: A tool for estimating water quality and, Computers and Geosciences, UK, vol. 45, pp 313-318, 2012.

[5] Zhouhu WU, Jian Z, Jie Z, Jie R, Shan C. A monitoring project planning technique of the water quality spatial distribution in Nansi Lake, $3^{\text {rd }}$ International Conference on Environmental Science and Information Application Technology, China, vol. 10, pp 2320-2328, 2011.

[6] Gürsoy Ö, Birdal AC, Özyonar F, Kasaka E. Determining and monitoring the water quality of Kizilirmak River of Turkey: First results, The International Achieves of Photogrammetry, Remote Sensing and Spatial Information Sciences, Germany, vol. 7, pp 1469-1474, 2015.

[7] Lewis P, O'Dwyer S, Disney MI, Hobsona P, Cutter M, Lobb D. On the potential of CHRIS/PROBA for estimating vegetation canopy properties from space, Remote Sensing Reviews, UK, vol. 19, pp 171-189, 2000.

[8] Guanter L, Alonso L, Moreno J. First results from the PROBA/CHRIS hyperspectral/multiangular satellite system over land and water targets, IEEE Geoscience and Remote Sensing Letters, USA, vol. 2, pp 250-254, 2005.

[9] URL 1: Republic of Turkey, Ministry of Environment and Urbanization, Laws on Management of Water Pollution (2004) www.csb.gov.tr/db/cygm/editordosya/YON25687SKKY.docx

[10] Chang C. Spectral information divergence for hyperspectral image analysis, IEEE 1999 International Geoscience and Remote Sensing Symposium, Germany, vol. 1, pp 509-511, 1999.

[11] Harsanyi J, Chang C. Hyperspectral Image Dimensionality Reduction and Pixel Classification: An Orthogonal Subspace Projection Approach, IEEE Transactions on Geoscience and Remote Sensing, USA, vol. 32, pp 779-758, 1994. 